\title{
Severe Hemorrhagic Syndrome After Lonomia Caterpillar Envenomation in the Western Brazilian Amazon: How Many More Cases Are There?
}

João Hugo A. Santos, MD, PhD; Sâmella S. Oliveira, MSc; Eliane C. Alves, MSc; Iran Mendonça-da-Silva, MD, MSc; Jacqueline A.G. Sachett, MSc; Antonio Tavares, MD; Luiz Carlos Ferreira, MD, PhD; Hui Wen Fan, MD, $\mathrm{PhD}$; Marcus V.G. Lacerda, MD, PhD; Wuelton M. Monteiro, PhD

From the Directorate of Education and Research, Fundação de Medicina Tropical Doutor Heitor Vieira Dourado, Manaus, Brazil (Drs Santos, Mendonça-da-Silva, Tavares, Ferreira, Lacerda, and Monteiro); School of Health Sciences, Universidade do Estado do Amazonas, Manaus, Brazil (Ms Oliveira, Alves, and Sachett, and Drs Mendonça-da-Silva and Monteiro); Venoms and Antivenoms Strategic Board, Instituto Butantan, São Paulo, Brazil (Dr Fan); and the Leônidas \& Maria Deane Research Institute, Fundação Oswaldo Cruz, Manaus, Brazil (Dr Lacerda).

\begin{abstract}
Contact with Lonomia caterpillars can cause a hemorrhagic syndrome. In Brazil, Lonomia obliqua and Lonomia achelous are known to cause this venom-induced disease. In the Brazilian Amazon, descriptions of this kind of envenomation are scarce. Herein, we report a severe hemorrhagic syndrome caused by Lonomia envenomation in the Amazonas state, Western Brazilian Amazon. The patient showed signs of hemorrhage lasting 8 days and required Lonomia antivenom administration, which resulted in resolution of hemorrhagic syndrome. Thus, availability of Lonomia antivenom as well as early antivenom therapy administration should be addressed across remote areas in the Amazon.
\end{abstract}

Keywords: hemorrhagic syndrome, Lonomia, caterpillar envenomation, antivenom, erucism

\section{Introduction}

Some larval lepidopteran insects may cause envenomation via contact with their bristles. ${ }^{1}$ In Brazil, the national surveillance system recorded a total of 35,117 cases of caterpillar injuries between 2000 and 2013. These injuries showed notable increasing trend from 216 cases in 2000 ( 0.1 cases $/ 100,000$ inhabitants) to 3488 in 2013 ( 1.8 cases/100,000 inhabitants), possibly related to an improvement in surveillance sensitivity over time. ${ }^{2}$ In 2013, the incidence was higher in Southern Brazil (4.2 cases $/ 100,000$ inhabitants) in comparison with the Brazilian Amazon (1.5 cases/100,000 inhabitants). The number of cases officially recorded in the Amazon is probably underestimated because of underreporting, since local indigenous and riverine populations do not have easy access to health centers.

Corresponding author: Wuelton M. Monteiro, $\mathrm{PhD}$, Fundação de Medicina Tropical Dr. Heitor Vieira Dourado, Avenida Pedro Teixeira 25, Dom Pedro, 69040-000, Manaus, AM, Brazil; e-mail: wueltonmm@ gmail.com.

Submitted for publication June 2016.

Accepted for publication November 2016.
Most caterpillar injuries are caused by the larvae of several species belonging to the Megalopigydae and Saturniidae families. These taxa cause envenomations that have individually indistinguishable local symptomology, described as immediate burning pain, erythema, edema, and immediate lymphangitis; in later stages, there may be vesicles, bullae, erosions, petechiae, superficial skin necrosis, and ulcerations. ${ }^{1}$ Only Lonomia spp (Saturniidae) can cause systemic complications, such as hemorrhagic syndrome and acute renal failure ${ }^{3-6}$ and result in fatalities. ${ }^{7}$ Before the introduction of specific antivenom for Lonomia spp, 10 fatalities attributed to hemorrhagic complications occurred among 26 workmen in Pará state (Eastern Brazilian Amazon) who were tapping rubber trees when envenomed ${ }^{8}$; in the Southern region, 4/155 patients envenomed by Lonomia died from reported massive hemorrhage. ${ }^{9}$

Two species of Lonomia are known to cause hemorrhagic syndrome: Lonomia achelous and Lonomia obliqua. ${ }^{6-8}$ L achelous is found in the Amazonian portions of Brazil, Venezuela, Colombia, Peru, Ecuador, and in the Guianas. ${ }^{10,11} L$ obliqua is found in the non-Amazonian area of Brazil, Paraguay, Argentina, and Uruguay ${ }^{10}$ and can cause disseminated intravascular coagulation and a 
consumptive coagulopathy, leading to hemorrhagic syndrome. ${ }^{11}$ Other Lonomia species found in the Amazon basin are Lonomia descimoni and Lonomia cynira, which may be also associated to envenomations. ${ }^{10}$ However, to the best of our knowledge, there have been no cases of hemorrhagic syndrome caused by Lonomia in this region.

Herein, we report a severe hemorrhagic syndrome after Lonomia caterpillar envenomation in Manaus, in the state of Amazonas.

The publication of this case report was approved by the Ethics Review Board of the Fundação de Medicina Tropical Doutor Heitor Vieira Dourado (approval number 713.140/2014).

\section{Case report}

A 58-year-old fisherman, previously healthy, accidentally came into contact with caterpillars on his right forearm in a riverine community located in the rural area of Manaus, Amazonas state, Brazil (Figure 1A). The patient reported that the contact was made with several caterpillars. After contact (day 0), he experienced an immediate local burning pain, erythema, and paresthesia at the site of contact. Around 24 hours after contact (day 1), he reported the occurrence of bleeding gums (Figure 1B) and bleeding from recent excoriations. Four days after contact (day 4), he reported the persistence of symptoms and was admitted to the Fundação de Medicina Tropical Doutor Heitor Vieira Dourado, a reference tertiary center for infectious and dermatologic diseases in Manaus, Amazonas state. Upon admission, this patient presented bleeding gums, epistaxis, and ecchymoses in upper limbs and abdomen. Laboratory analyses revealed blood incoagulability. On day 4, the patient brought caterpillars that were identified as Lonomia sp at the Butantan Institute (Prof. Roberto Henrique Pinto Moraes) (Figures 1C and 1D).

On day 6, the patient's symptoms persisted (bleeding gums, ecchymoses in upper limbs and abdomen). Laboratory investigation revealed prothrombin activity of

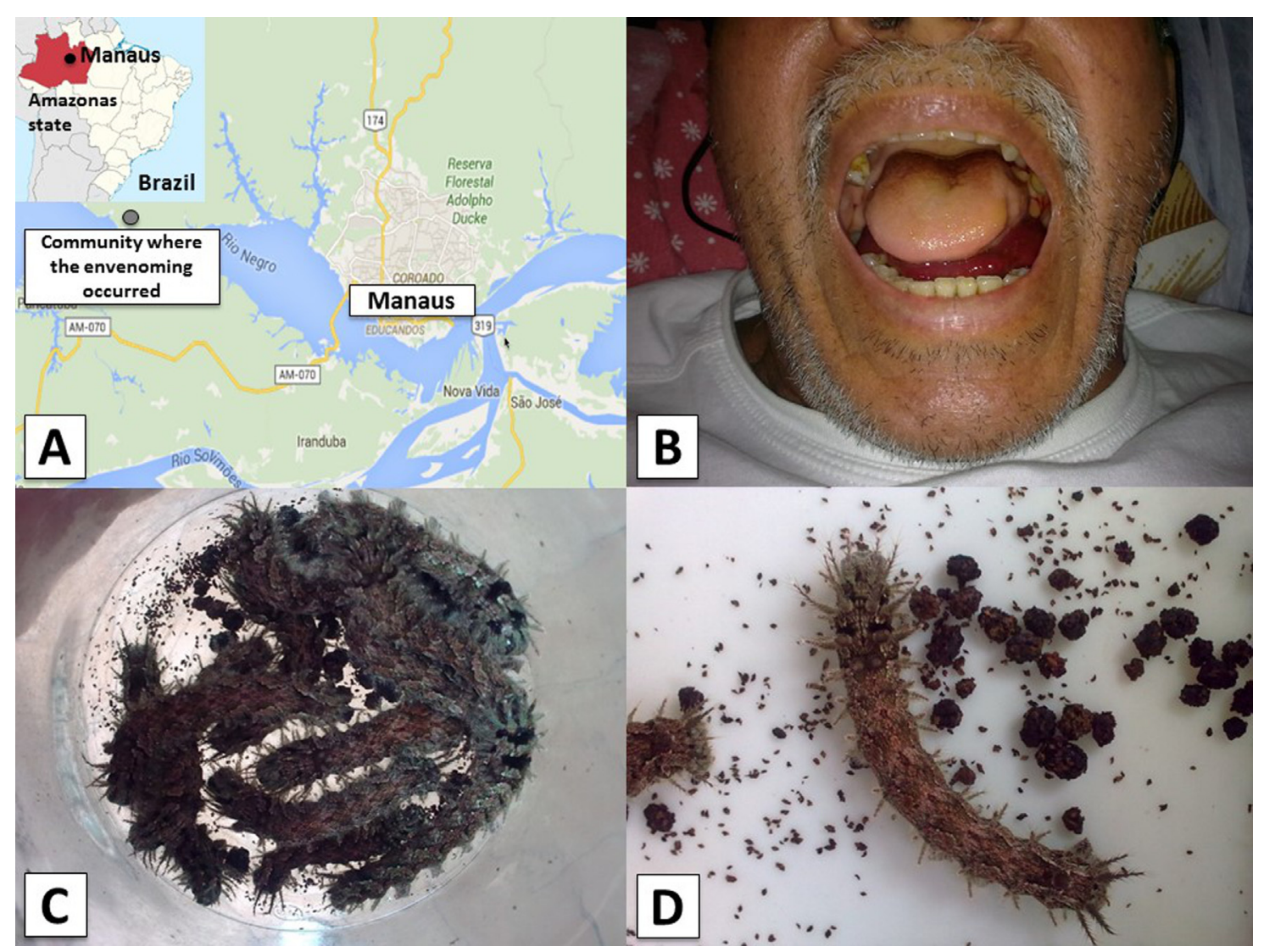

Figure 1. Spatial location, clinical picture and agent of the Lonomia envenomation case. A, Geographic location of the community in the rural area of Manaus, Amazonas state, Western Brazilian Amazon, in which the envenomation occurred. B, Bleeding gums and sublingual bleeding observed 8 days after envenomation (day 8). C and D, Lonomia specimens responsible for the envenomation brought by the patient on admission. 


\section{Days after envenomation}

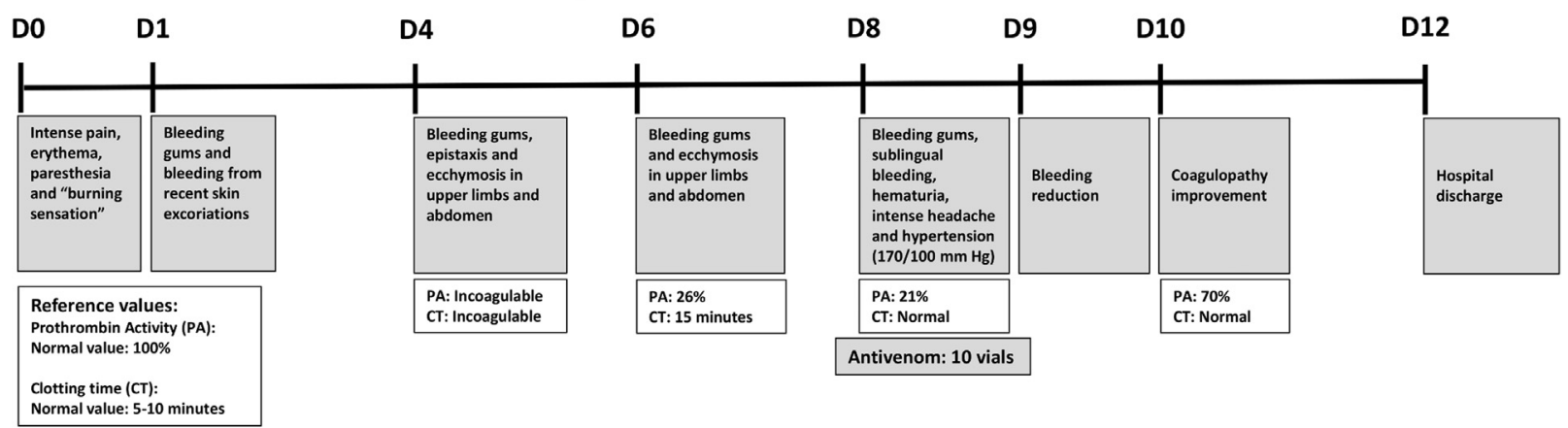

Figure 2. The clinical evolution and management of the Lonomia spp. envenomed patient, from the day of the envenomation until hospital discharge.

$26 \%$ and clotting time of 15 minutes on day 6 and prothrombin activity of $21 \%$ and normal clotting time on day 8 . Physical examination still revealed bleeding gums and sublingual bleeding, ecchymoses in upper limbs and abdomen, hematuria, and hypertension $(170 / 100 \mathrm{~mm}$ $\mathrm{Hg}$ ). Intense headache was reported by the patient at this time. Ten vials of Lonomia antivenom were administered after premedication with intravenous hydrocortisone, oral dexchlorpheniramine, and intravenous ranitidine, following the hospital routine.

From day 8 onward, the patient showed clinical improvement with reduction of bleeding signs. Computed tomography scans of the head (day 8) and ultrasonography of the abdomen and right upper limbs (day 10) showed no abnormalities. On day 10 , blood coagulation tests returned to normal values, and bleeding signs ceased. The patient recovered well, and he was discharged on day 12 .

Clinical picture and evolution of the patient are described in Figure 2.

\section{Discussion}

Lonomia envenomations with hemorrhagic syndrome occur primarily in Southern Brazil. ${ }^{1,10}$ In the Brazilian Amazon, Lonomia caterpillar envenomation was originally described as an occupational disease among rubber tappers, with reports of patients with systemic bleeding in the Amapá and Pará states. ${ }^{8}$ In this study, we reported a severe Lonomia envenomation in the Western Brazilian Amazon, more precisely in a rural area of Manaus, the capital of Amazon state, in a conservation unit located about $25 \mathrm{~km}$ from downtown. This area is inhabited by riverine communities and is frequently visited by locals and foreign tourists who use the Negro River for recreational purposes.
Consumptive coagulopathy and secondary fibrinolysis are the main cause of bleeding complications observed in patients after contact with $L$ obliqua ${ }^{11}$ and $L$ achelous. ${ }^{6}$ Studies show that $L$ obliqua caterpillar bristle extract displays procoagulant activity that leads to intravascular thrombin formation, resulting in a special form of disseminated intravascular coagulation. Key molecules in L obliqua caterpillar bristle extract are a prothrombin and factor $\mathrm{X}$ activator. ${ }^{12}$ Fibrinolysis seems to be secondary to the fibrin production, since no direct fibrinolytic activity was found in the bristle extract. ${ }^{12,13}$

Lonomia caterpillars live in tree bark colonies, which may lead to human contact with large numbers of caterpillars, thus exposing victims to a larger amount of venom and influencing the intensity of subsequent clinical manifestations. ${ }^{1}$ The high amount of circulating venom and the delay in seeking treatment at the health service after contact with the caterpillar could explain the severity observed in the reported case. This patient showed hemorrhagic manifestations on the second day after contact with Lonomia caterpillars, but he did not seek treatment until the fourth day. In general, hemorrhagic manifestations can appear within a few hours or days after contact with the caterpillar bristles. ${ }^{5}$ Thus, Lonomia envenomation may be diagnosed late in patients presenting with severe systemic manifestations, such as pulmonary or intracerebral hemorrhage $e^{3,7}$ and acute renal failure. ${ }^{4}$

Diagnosis of Lonomia envenomation is based on the presence of coagulopathy or systemic haemorrhage in a patient who had skin contact with caterpillars in the previous 48 hours. The Brazilian Ministry of Health established the severity criteria in 3 grades $^{1}$ : 1) mild cases show only local manifestations; 2) moderate cases may include local manifestations and bleeding in skin/ mucous membranes and mild coagulopathy; and 3) severe cases occur with previous symptoms associated 
with visceral or life-threatening bleeding. No antivenom is recommended for mild cases, while the recommended treatments for moderate and severe Lonomia envenomations are administration of 5 and 10 vials of specific antivenom, respectively. Each vial $(10 \mathrm{~mL})$ of Lonomia antivenom contains heterologous $\mathrm{F}\left(\mathrm{ab}^{\prime}\right) 2$, neutralizing at least $3.5 \mathrm{mg}$ of L obliqua venom. ${ }^{14,15}$ In this case, the patient was classified as severe and received the correct antivenom dosage 8 days after contact with Lonomia. However, severity of this case was partly because the patient was treated days after envenomation. Clinical studies have shown that specific antivenom is effective for Lonomia envenomation treatment, reverting coagulation disorders within 24 hours after administration, ${ }^{16}$ in agreement with our findings. Although the evidence for premedication with antihistamines and corticosteroids is limited, this is routine in the hospital at which the patient was treated. In this case report, no adverse reactions to antivenom were seen.

Lonomia antivenom was first manufactured in 1994 and continues to follow nearly the same $\operatorname{steps}^{14,15}: 1$ ) collection of $L$ obliqua bristle extract from caterpillars collected from different regions; 2) immunization and bleeding of adult horses; and 3) purification of plasma and formulation of $F\left(a b^{\prime}\right) 2$ fragments of immunoglobulins. The bulk is bottled in glass vials $(10 \mathrm{~mL})$, labelled, packed, and stored at temperatures of under $2^{\circ} \mathrm{C}$ to $8^{\circ} \mathrm{C}$. Instituto Butantan is the sole manufacturer of Lonomia antivenom, which is distributed by the Ministry of Health to the whole country. There is an ongoing study to validate the use of Butantan's Lonomia antivenom in other South American countries where Lonomia caterpillars also constitute a health problem. Aside from specific antivenom therapy, there are no other effective treatments to reverse the effects of Lonomia envenomation. Antifibrinolytic drugs, such as epsilonaminocaproic acid or aprotinin, and vitamin $\mathrm{K}$ have shown no therapeutic efficacy, may be harmful, and are contraindicated in the management of Lonomia envenomation. ${ }^{16}$

\section{Conclusion}

This case report details a severe case of Lonomia envenomation in the Brazilian Amazon, a neglected clinical condition in this region. However, it is necessary to assess Lonomia envenomation burden through population- and hospital-based field studies in remote areas. This report underscores the need for prompt availability of Lonomia antivenom and early treatment as a prognostic factor of victims. Specific antivenom was effective in resolution of hemorrhagic syndromes even days after caterpillar contact. Investments in training health professionals are critical for correct management of the patient and follow-up of possible complications.

Acknowledgments: We thank the clinical and laboratorial staff of the Fundação de Medicina Tropical Dr. Heitor Vieira Dourado.

Author Contributions: Study concept and design (MVGL, WMM); acquisition of the data (JHAS, JAGS, IMS); analysis of the data (JHAS, JAGS, IMS); drafting of the manuscript (SSO, ECA, HWF, MVGL, WMM); critical revision of the manuscript (MVGL, WMM); and approval of final manuscript (JHAS, SSO, ECA, IMdS, JAGS, AT, LCF, HWF, MVGL, WMM).

Financial/Material Support: This study was funded by FAPEAM. MVGL is a level 1 fellow from CNPq. The funders had no role in study design, data collection and analysis, decision to publish, or preparation of the manuscript.

Disclosures: None.

\section{References}

1. Wen HF, Duarte AC. Acidentes por Lonomia. In: Sarvier, ed. Venomous Animals in Brazil: Biology, Clinic and Therapeutics 2nd ed. São Paulo, Brazil: Sarvier; 2009:240-248.

2. Brazilian Ministry of Health, Lagartas. Situação Epidemiológica. 2015. Available at: portalsaude.saude.gov.br/ index.php/o-ministerio/principal/leia-mais-o-ministerio/ 1022-secretaria-svs/vigilancia-de-a-a-z/animais-peconhen tos-lagarta/12-animais-peconhentos-lagarta/13702-situa cao-epidemiologica-dados. Accessed March 23, 2016.

3. Duarte AC, Crusius PS, Pires CAL, Shilling MA, Wen FH. Intracerebral haemorrhage after contact with Lonomia caterpillars. Lancet. 1996;348:1033.

4. Gamborgi GP, Metcalf EB, Barros EJG. Acute renal failure provoked by toxin from caterpillars of the species Lonomia obliqua. Toxicon. 2006;47:68-74.

5. Málaque CM, Andrade L, Madalosso G, Tomy S, Tavares FL, Seguro AC. A case of hemolysis resulting from contact with a Lonomia caterpillar in southern Brazil. Am J Trop Med Hyg. 2006;74:807-809.

6. Arocha-Piñango CL, Bosch NB, Torres A, et al. Six new cases of a caterpillar-induced bleeding syndrome. Thromb Haemost. 1992;67:402-407.

7. Chan K, Lee A, Onell R, et al. Caterpillar-induced bleeding syndrome in a returning traveller. CMAJ. 2008;179: 158-161.

8. Fraiha H, Ballarini A, Leão R. Síndrome hemorrágica por contato com larvas de mariposa (Lepidoptera, Saturniidae). Inst Evandro Chagas, 50 anos Contrib às ciências biológicas e a Med Trop. 1986;2:811-818.

9. Kelen EMA, Picarelli ZP, Duarte AC. Haemorrhagic syndrome induced by contact with caterpillars of the genus Lonomia (Saturniidae, Hemileucinae). J Toxicol-Toxin Rev. 1995; 14:283-308.

10. Lemaire C. Révision du genre Lonomia Walker (Lep. Attacidae). Ann Soc Ent Fr. 1972;8:707-861.

11. Zannin M, Lourenço DM, Motta G, et al. Blood coagulation and fibrinolytic factors in 105 patients with 
hemorrhagic syndrome caused by accidental contact with Lonomia obliqua caterpillar in Santa Catarina, southern Brazil. Thromb Haemost. 2003;89:355-364.

12. Chudzinski-Tavassi AM, Carrijo-Carvalho LC. Biochemical and biological properties of Lonomia obliqua bristle extract. J Venom Anim Toxins Trop Dis. 2006;12:156-171.

13. Carrijo-Carvalho LC, Chudzinski-Tavassi AM. Biochemical and biological properties of Lonomia obliqua bristle extract. Toxicon. 2007;49:741-757.

14. Rocha-Campos AC, Gonçalves LR, Higashi HG, et al. Specific heterologous $\mathrm{F}\left(\mathrm{ab}^{\prime}\right) 2$ antibodies revert blood incoagulability resulting from envenoming by Lonomia obliqua caterpillars. Am J Trop Med Hyg. 2001;64:283-289.

15. Dias da Silva W, Campos CM, Gonçalves LR, et al. Development of an antivenom against toxins of Lonomia obliqua caterpillars. Toxicon. 1996;34:1045-1049.

16. Gonçalves LR, Sousa-e-Silva MC, Tomy SC, SanoMartins IS. Efficacy of serum therapy on the treatment of rats experimentally envenomed by bristle extract of the caterpillar Lonomia obliqua: comparison with epsilon-aminocaproic acid therapy. Toxicon. 2007;50: 349-356. 